\title{
Assessing Ecological Indicators for Remnant Vegetation Strips as Functional Biological Corridors in Chilean Vineyards
}

\author{
Javiera Díaz-Forestier ${ }^{1}$, Sebastián Abades ${ }^{2}$, Nélida Pohl ${ }^{3}$, Olga Barbosa ${ }^{3,4}$, Karina Godoy ${ }^{3,4}$, \\ Gabriella L. Svensson ${ }^{5}$, María I. Undurraga ${ }^{3}$, Camila Bravo ${ }^{6}$, Camila García ${ }^{7}$, Meredith Root-Bernstein ${ }^{3,8}$, \\ Juan J. Armesto ${ }^{3,9,10}$ and Juan L. Celis-Diez $7, *(\mathbb{D}$
}

Citation: Díaz-Forestier, J.; Abades S.; Pohl, N.; Barbosa, O.; Godoy, K.; Svensson, G.L.; Undurraga, M.I.; Bravo, C.; García, C.; Root-Bernstein, M.; et al. Assessing Ecological Indicators for Remnant Vegetation Strips as Functional Biological Corridors in Chilean Vineyards. Diversity 2021, 13, 447. https:/ / doi.org/10.3390/d13090447

Academic Editor:

Panayiotis Dimitrakopoulos

Received: 30 July 2021

Accepted: 13 September 2021

Published: 19 September 2021

Publisher's Note: MDPI stays neutral with regard to jurisdictional claims in published maps and institutional affiliations.

Copyright: (c) 2021 by the authors. Licensee MDPI, Basel, Switzerland. This article is an open access article distributed under the terms and conditions of the Creative Commons Attribution (CC BY) license (https:// creativecommons.org/licenses/by/ $4.0 /)$.
1 Centro Regional de Investigación e Innovación para la Sostenibilidad de la Agricultura y los Territorios Rurales_CERES, Quillota 2260000,Chile; javi@litre.cl

2 GEMA Center for Genomics, Ecology \& Environment, Facultad de Estudios Interdisciplinarios, Universidad Mayor, Santiago 8580745, Chile; sebastian.abades@umayor.cl

3 Instituto de Ecología y Biodiversidad, IEB, Santiago 7800003, Chile; nelypohl@gmail.com (N.P.); olgabarbosa@gmail.com (O.B.); karinagodoym@gmail.com (K.G.); maundurr@uc.cl (M.I.U.); mrootbernstein@gmail.com (M.R.-B.); jarmesto@bio.puc.cl (J.J.A.)

4 Instituto de Ciencias Ambientales y Evolutivas, Facultad de Ciencias, Universidad Austral de Chile, Valdivia 5090000, Chile

5 Gerencia de Áreas Silvestres Protegidas del Estado, Corporación Nacional Forestal, CONAF, Santiago 8330478, Chile; gabi.linnea@gmail.com

6 Departamento de Ciencias Ecológicas, Facultad de Ciencias, Universidad de Chile, Santiago 7800003, Chile; camibravo@ug.uchile.cl

7 Escuela de Agronomía, Pontificia Universidad Católica de Valparaíso, Quillota 2260000, Chile; camigarbea@gmail.com

8 UMR CESCO, CNRS, Musée National d'Histoire Naturelle, 75005 Paris, France

9 Facultad de Ciencias Naturales y Oceanográficas, Universidad de Concepción, Concepción 4070386, Chile

10 Facultad Ciencias Biológicas, Pontificia Universidad Católica de Chile, Santiago 8331150, Chile

* Correspondence: juan.celis@pucv.cl; Tel.: +56-9-9228-4640

Abstract: Mediterranean central Chile is globally recognized as a hotspot for terrestrial biodiversity due to its high endemism and massive habitat loss. However, within the rural landscape of central Chile, significant extents of natural areas remain, especially on less productive, steep slopes, and vegetation strips extending from the surrounding hills to agricultural areas. Accordingly, vegetation strips or corridors, within lowland farms, constitute key elements to support the conservation of biodiversity in rural landscapes. To assess the ecological performance of corridors in 22 commercials vineyards in central Chile, we characterized them in terms of width-, length-, area-, and perimeter-toarea ratios, as well as the number of connections with natural areas. Based on a set of previously defined ecological indicators (species, functional groups, and structural components), we compared their occurrence in corridors within vineyards and in the surrounding natural areas. We evaluated the effects of corridor attributes on the occurrence of the selected ecological indicators, using a generalized linear mixed model with each vineyard as a random factor. The area, width, and length of vegetation corridors varied widely (1.2-86.3 ha, 10.5-95 m, and 380-5000 m, respectively). We found significant differences in the occurrence of indicators between corridors and natural areas. All sampled ecological indicators in corridors showed a negative relationship with the distance to the nearest natural area. Vegetation strips within vineyards represent important opportunities for biodiversity conservation that significantly enhance habitat quality in the agricultural landscape for biodiversity and habitat connectivity.

Keywords: land-sharing; vinecology; ecological intensification; vegetation corridors; agricultural landscapes; ecological indicators 


\section{Introduction}

Increasing ecological intensification for sustainable agriculture, in addition to landscape connectivity approaches (i.e., wildlife-friendly farming systems), have promoted a greater interest in assessing the benefits that preserved natural ecosystems could provide to farmland [1-3]. This assessment is valuable because of the strong links recently found between biodiversity and sustainable crop yields [4]. Moreover, ecosystem benefits to agricultural production are declining, due to the expansion of cultivated lands, which is a driver of habitat change and biodiversity loss, resulting in a reduction in nature's contributions to people and quality of life [5-7]. This is a serious problem, especially in biodiversity-rich Mediterranean-climate regions [8], where climate suitability has favored the successful expansion of agriculture and forestry plantations [9-11]. Generally, these regions are characterized by the limited amount of land set aside for protected areas, due to a high-opportunity cost associated with urban expansion and agriculture [10,12].

In Chile, protected areas represent only $1-3 \%$ of the original land cover [13] and are small, scattered, and lack biological connections to one another [14]. However, given the geography of the area, natural remnants remain dispersed within agricultural landscapes, including larger areas in less productive zones and steep slopes, as well as vegetation strips that project from hillsides into agricultural areas and hedgerows [10,15].

Remnant habitats in productive land offer conservation a foothold while also enhancing ecosystem service provision for sustainable agricultural production $[1,2,16]$, in addition to promoting a historical-cultural landscape, which is very attractive for the development of agro-tourism at a global scale [17-19].

There is a growing awareness among farmers of a paradigm shift that promotes agricultural production while minimizing adverse effects on the environment [20-22]. This has led to initiatives enhancing biodiversity conservation and sustainability in vineyards and in other agricultural landscapes $[3,23,24]$. One local example is a pioneering and globally recognized initiative (awarded in 2018 with the Green Awards by the Drinks Business) known as the "Wine, Climate Change and Biodiversity" program (VCCB, by its acronym in Spanish) of the Chilean Institute of Ecology and Biodiversity. The wine industry is now transitioning from sustainability awareness to concrete and innovative management practices in the region [23,25]. However, further monitoring and evaluation of management actions, in a way that is feasible for practitioners, seems necessary, including research-based support, monitoring ecological indicators, and assessing improvements [26,27]. However, as recently discussed by Bal et al. [27], indicators must be selected a priori and applied depending on the local context, ensuring reliable management decisions and monitoring strategies [28]. In this work, we critically assess one of the most relevant conservation practices adopted by the Chilean grape growers in central Chile: "To maintain forest and scrubland strips within vineyards" areas [see 25]. Planted vineyards in California, Chile, and South Africa maintain remnants of native vegetation, such as greenways or vegetation strips [23,29], landscape drainage corridors, and/or soil protection on steep, fragile slopes [30]. A recent survey of conservation practices adopted by winegrowers indicated that $100 \%$ of the Chilean vineyards participating in the study $(n=14)$ had implemented "biological corridors" within their land [25], which is what these remnants of native vegetation or strips, immersed within the crop area, are commonly called by winegrowers.

Biological corridors can act as habitats for some species and act as animal passageways from one area to another [31,32]. A growing body of evidence in the scientific literature concerns the importance of biological corridors for biodiversity and their role in the connectivity in rural and urban landscapes [3,33]. Usually, these works have focused on the response of biodiversity indicators, i.e., taxa that reflect the state of the wider biodiversity, are reactive to disturbance, and function as early warning signals for harmful and unpredictable changes in the environment $[27,34]$. Depending on the spatial scale, different ecological indicators could have different responses to landscape changes [35]. In this work, we want to consider this approach from the perspective of stakeholders, hence providing effective tools for those who manage productive landscapes. 
To assess the ecological performance of these "biological corridors" in Chilean vineyards, here we addressed following general questions. What are the salient features of existing vegetation corridors in vineyards? What are their benefits for biodiversity conservation? Are biological corridors useful for different organisms (e.g., plants and birds), in terms of connectivity in the rural landscape? Given that biological corridors are frequent landscape features intended to enhance conservation of biodiversity in agricultural areas [3], assessing their performance is critical. Several aspects of corridor design at the landscape scale, such as area-, shape-, or edge-to-interior ratio, could make a difference, regarding the goal of conserving biodiversity and nature's contributions to people [31,32]. Here, we characterize biological corridors in Chilean vineyards, with the aim of deriving useful insights for the future design and evaluation of key ecological processes operating in these productive lands. We compared habitat corridors for biodiversity conservation found within vineyards with the surrounding native vegetation, considered as a reference system, using a set of ecological indicators (see above) that included functional, structural, and compositional dimensions of biodiversity [36]. We selected ecological indicators for monitoring and evaluating potentially beneficial management actions, in a way that is feasible for practitioners. We hypothesized that: (i) Wider and more connected corridors could favor the presence of all ecological indicators. (ii) Resident ecological indicators (i.e., plants) in corridors were expected to relate to the corridor area, according to the predictions of island biogeography theory, i.e., the species were more likely to be lost from corridors with lower areas (or far from large natural remnants (sources)) than from large corridors (or close to natural areas). These indicators should be more affected by the distance from farmland to large remnant vegetation areas and by edge-to-interior ratios in corridors (i.e., birds).

In summary, we asked what corridor features can predict the presence of selected biodiversity indicators, and which corridor features contribute the most to overall indicator richness. Results from this study are expected to provide a better understanding of the relationship between landscape features and biodiversity/ecosystem services in productive systems, which, in turn, could lead to improved strategies for mitigating the negative impacts on the biodiversity of current and future agricultural developments.

\section{Materials and Methods}

We characterized one remnant natural vegetation strip (mostly the only or main one) within cultivated areas found in 22 different vineyards of central Chile (Figure 1). These vegetation strips $(n=22)$ were identified as "biological corridors" by farmers [25] (hereafter "corridors").

This study was conducted within vineyards belonging to some of the most important wine producers in central Chile, which includes about $10 \%$ of the total number of central Chilean wineries. To characterize biological corridors (as defined above), we measured: (i) Mean corridor width; (ii) Total corridor area; (iii) Corridor length (starting from the natural area to corridors end); (iv) Branching pattern, as the number of secondary strips connecting the main vegetation strip to natural vegetation areas adjacent to the vineyard; (v) The ratio of the corridor-area-to-total-cultivated-area, using the corridor-to-farmland ratio at each vineyard; (vi) The ratio of the number of branches connecting to natural areas over corridor length; and (vii) The corridor-perimeter-to-area ratio. Characteristics of each "corridor" or vegetation strip sampled are presented in Table S1 (Supplementary Material). Vegetation cover data for vineyards were obtained from Sentinel-2 images for the year 2013, complemented by field surveys. Image processing for polygon delineation was done in ArcGis v10 software, Extension Spatial Analyst 10. 


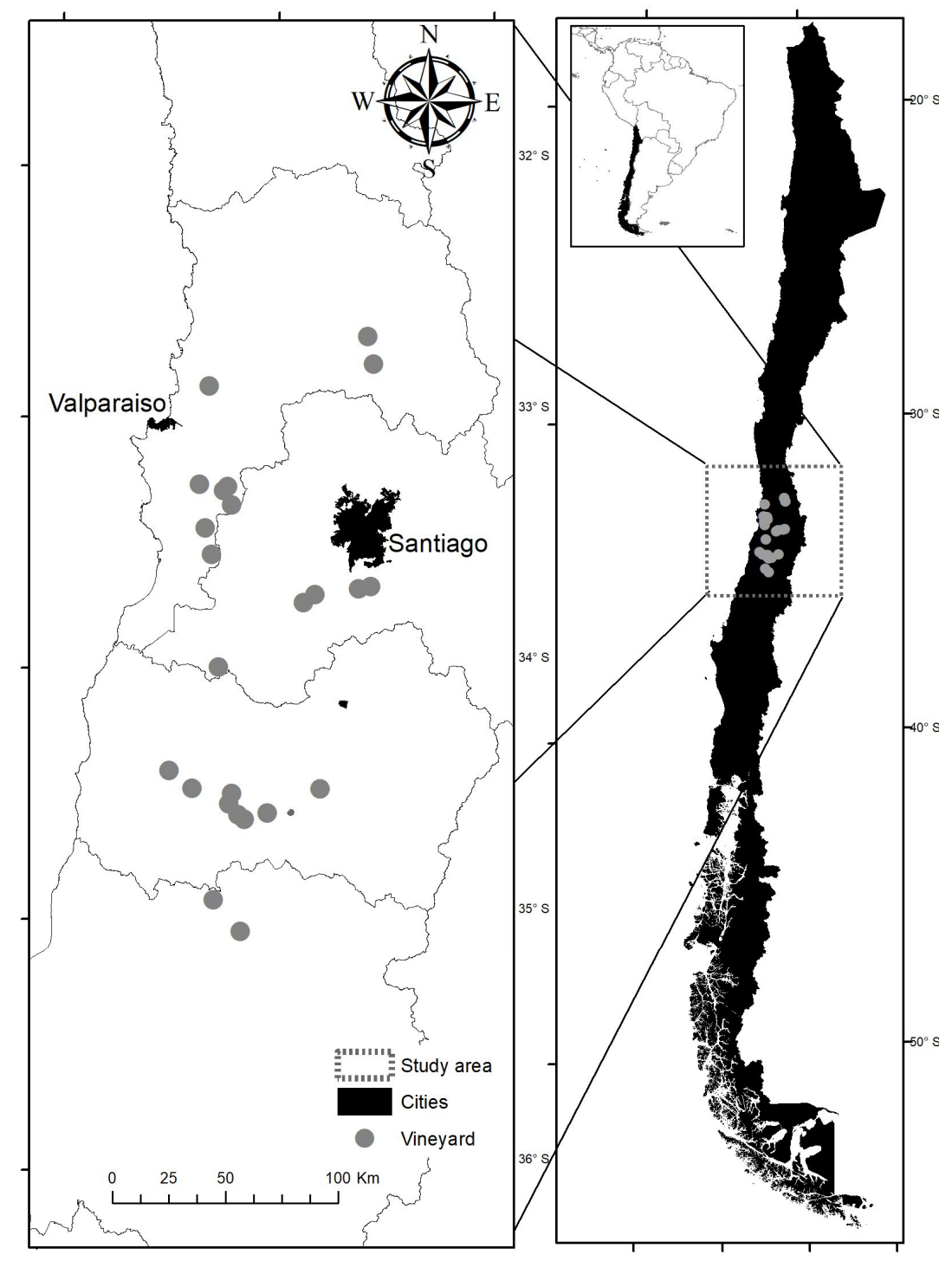

Figure 1. Map of central Chile showing the location of study sites. Gray circles indicate sampled vineyards, found mostly in the central valley and coastal range.

For comparing corridor function in the landscape, we proposed a set of four types of ecological indicators, considering the functional, structural, and compositional dimensions of biodiversity. Our selection of indicators for this landscape was based on consultation with experts [27], previous studies, and analysis of the available literature on the natural history and behavior of species.

We sampled the area, considering the following ecological indicators: (i) Selected bird species. Based on their ecological requirements, we selected 5 avian species from three different functional groups in central Chile, which have different habitat preferences. These species were: the primary cavity nester striped woodpecker (Dryobates lignarius: Picidae) and the secondary cavity nester thorn-tailed rayadito (Aspharastura spinicauda: Furnariidae), both of which occur in sites with dense tree cover, including the presence of some large, old trees for nesting and successful reproduction [37]. Additionally, we included three endemic understory birds that depend on dense understory cover for shelter, movement, and reproduction [38], such as the rhinocryptids dusky tapaculo (Scytalopus fuscus), the white-throated tapaculo (Scelorchilus albicollis), and the Moustached turca (Pteroptochos megapodius). These species are all insectivorous, which are more susceptible than other bird functional groups to habitat degradation and loss [39,40]. We assessed the occurrence of these birds in the vegetation strips sampled using call playbacks. Using 
a JBL charge speaker $(2 \times 5 \mathrm{~W})$ for playback, one survey team member stayed close to the speaker to control the playback, and the other team member moved away from this central location (>50 m from the speaker) to increase detection. Playback calls for each bird species were played three times, at intervals of $15 \mathrm{~s}$, to enhance detection rates. (ii) Tree regeneration-natural regeneration of sclerophyllous trees within the vegetation corridors and in areas of remnant vegetation may be limited by biotic/abiotic ecological filters. Limited seed availability, summer desiccation (water shortage), and the impacts of herbivory on seeds and seedlings, especially by invasive exotic species (e.g., rabbits), constrain seedling recruitment [41]. We quantified the presence/absence of seedlings or saplings ( $<1 \mathrm{~cm}$ diameter at breast height) of sclerophyllous tree species in all corridors and adjacent natural areas. (iii) Geophytes - this group of plant species, which represents a $63.4 \%$ of the Chilean Mediterranean flora [42], is often ignored in vegetation surveys. These species are largely endemic to central Chile (70\%). Herbaceous plant diversity is often enhanced by the presence of small mammals in the Chilean matorral [43]. Geophyte recruitment can be promoted by the digging activities of endemic rodents (Octodon degus and Spalacopus cyanus), which consume the bulbs and store seeds [44]. Because the presence of vegetative geophytes is conspicuous in the field, we recorded their presence/absence in all corridors and adjacent natural areas. (iv) Woody plant coverage-in both vegetation corridors and remnant patches, we measured woody plant cover of trees, shrubs, and succulents, which can be affected by disturbances such as fire, logging, and cattle grazing, leading to progressive deterioration of forest structure, often resulting in a net loss of plant cover and species richness. In addition, shrubs are considered to be positively related to endemic herbaceous diversity [43]. Woody plant cover was estimated visually using standard cover ranges [45].

For each vineyard studied $(n=22)$, we selected 6 sites for surveying ecological indicators. Three sites randomly distributed across the selected vegetation corridors within the cultivated area and other three sites randomly distributed in a large remnant of adjacent natural vegetation present within 200 and $500 \mathrm{~m}$ from the vineyard edge (Figure 2). Sampling was also done within the planted crop but due to the total absence of the ecological indicators in plantations, results were not reported in this study. In each of the six sampled sites at each vineyard (i.e., three within the selected vegetation corridor and three within the adjacent natural remnant vegetation), we established a 5-m radius circular plot where we measured the selected ecological indicators (see above).

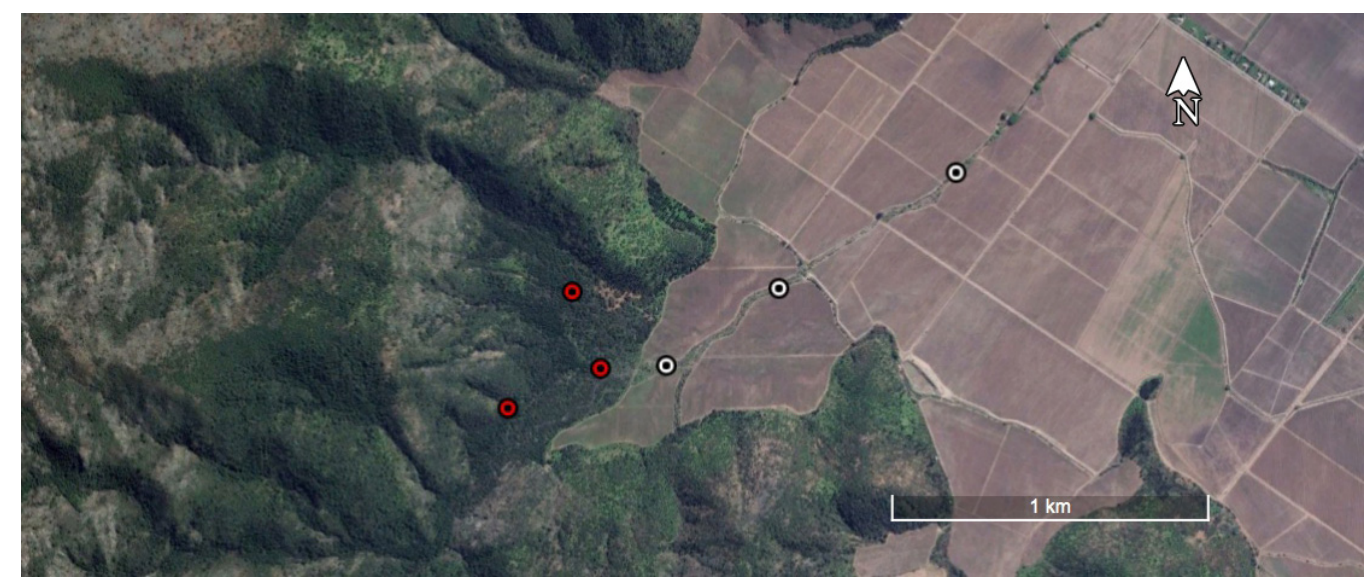

Figure 2. Image of vineyard in central Chile showing a typical farm landscape, including natural areas, cropland areas and vegetation strip corridors within crops. As shown in this landscape, we sampled six sites in this study: three sites within "corridors" (white circles) and three sites in adjacent natural vegetation (red circles), 200-500 m away from the cultivated areas. 


\subsection{Data Analysis}

\subsubsection{Corridors vs. Remnant Natural Areas}

To evaluate the importance of vegetation corridors and adjacent natural areas on the representation of each ecological indicator, we used a zero-inflated generalized linear mixed model to account for the potential excess of zeros (i.e., false negative observations), due to low detection probability of most of our selected ecological indicators within the study [46]. The fixed part of the model included the type of area compared (i.e., corridor vs. natural remnant), while the vineyard (i.e., site) was specified as a random component. The response variable was assumed to be Poisson-distributed for bird species (counts) and Binomial for tree regeneration, geophytes (presence/absence data), and woody plant cover (percentage). Model significance was tested by comparing it with the intercept-only model using the likelihood-ratio test.

\subsubsection{Effect of Corridor Features on Ecological Indicators}

To assess the effects of corridor attributes on our selected ecological indicators, we used a multimodel selection routine that compared all subset models that can be constructed using linear combinations of the following corridor attributes: corridor width (m), corridor length $(\mathrm{m})$, number of connections between the corridor and the surrounding natural area, length of connections $(\mathrm{m})$, distance between the randomly-selected sampled plot both in corridors and natural areas $(\mathrm{m})$, total areas of the vegetation corridors (ha), perimeterto-area ratio $(\mathrm{m} / \mathrm{ha})$, and the cultivated area versus corridor-area ratio (unitless). No interaction terms were included in the models to avoid overfitting. Each subset model was fitted using a generalized linear mixed model with Poisson assumption for the case of bird species and Binomial distribution for the remaining ecological indicators. The most parsimonious model was selected based on AIC [47]. All statistical analyses were carried out in R 3.6.1 (R CoreTeam), combining functions provided by the pscl [48], lmtest [49], glmmulti [50] and MuMIn [51] packages.

\section{Results}

\subsection{Corridor Characterization}

Sampled vegetation corridors $(n=22)$ corresponded primarily $(68 \%)$ to natural drainage corridors (or seasonal streams) within the cultivated landscape, including a basin and its tributaries (see Figure 2 for an example). These corridors usually ended in a cultivated patch, a road, or a degraded site, not in the surrounding natural vegetation due to the intensification of the landscape use in lowland areas. Drainage corridors connected the principal basin with the surrounding natural areas at several points. We also sampled corridors following irrigation channels $(9 \%)$ and road edges $(9 \%)$, or a combination of them $(13.6 \%)$. The average area of the 22 corridors sampled in the vineyards was 22 ha \pm 20.8 (mean \pm DS), and their width was $26.22 \pm 19.4 \mathrm{~m}$, respectively. Corridor perimeters were positively correlated with their area (Supplementary Material Figure S1). The area of corridors was variable and not related to the total area of the farms. Figure 3 summarizes the main characteristics of the sampled corridors. 

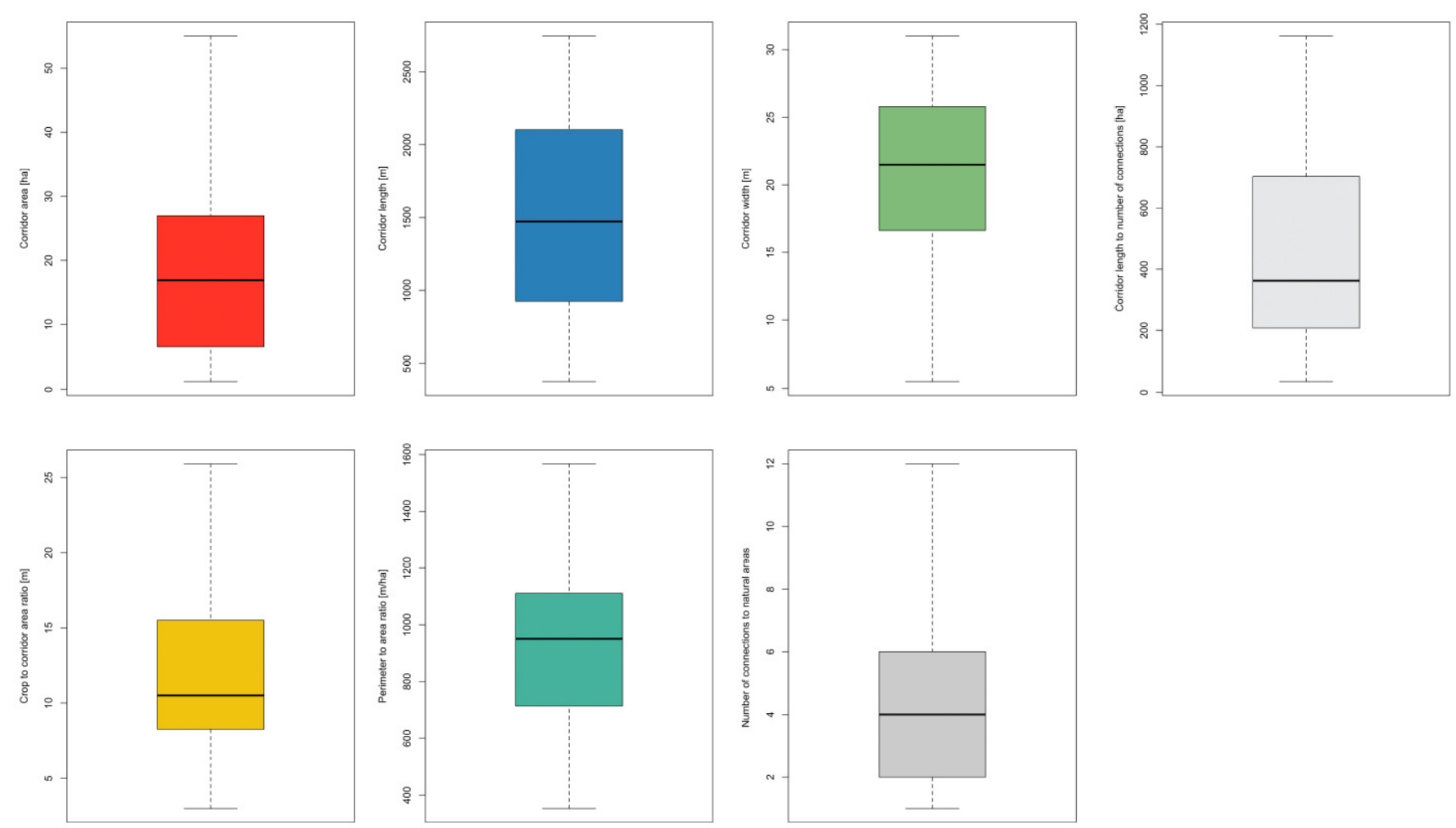

Figure 3. Box plots of attributes of the sampled corridors $(n=22)$.

\subsection{Corridors vs. Remnant Natural Areas}

Based on our analysis, total woody plant cover did not differ significantly between plots in natural areas and plots in corridors (likelihood-ratio test $X^{2}=1.059 ; \mathrm{gl}=1 ; p=0.303$; Figure 4, Supplementary Material Table S2). The number (richness) of the selected indicator bird species was higher in natural areas than in corridors (likelihood-ratio test $X^{2}=9.84$; $\mathrm{gl}=1 ; p=0.00172$; Figures 4 and 5, Supplementary Material Table S2). Scelorchilus albicollis, an endemic ground dwelling Rhinocryptid, was the only species that did not occur in the corridors sampled (Figure 5). The presence of geophytes was higher in plots within adjacent natural areas than in corridors within vineyards (likelihood-ratio test $X^{2}=4.31$; $\mathrm{gl}=1 ; p=0.045$, Figure 4, Supplementary Material Table S2), while the presence of tree regeneration did not differ between corridors and adjacent remnant areas of natural vegetation (likelihood-ratio test $\mathrm{X}^{2}=2.12 ; \mathrm{gl}=1 ; p=0.149$; Figure 4 , Supplementary Material Table S2).
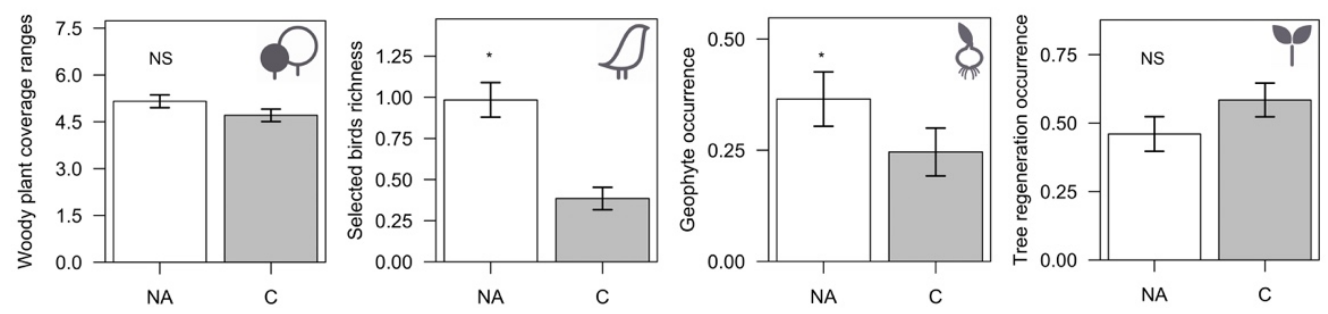

Figure 4. Differences in the frequency of the selected ecological indicators between remnant natural areas on adjacent slopes (NA), and vegetation strip corridors (C) within the vineyards. From left to right: "Woody plant coverage", "Bird species", "Geophytes", and "Tree regeneration". Significance: NS $=p>0.05,{ }^{*}=p \leq 0.05$. 


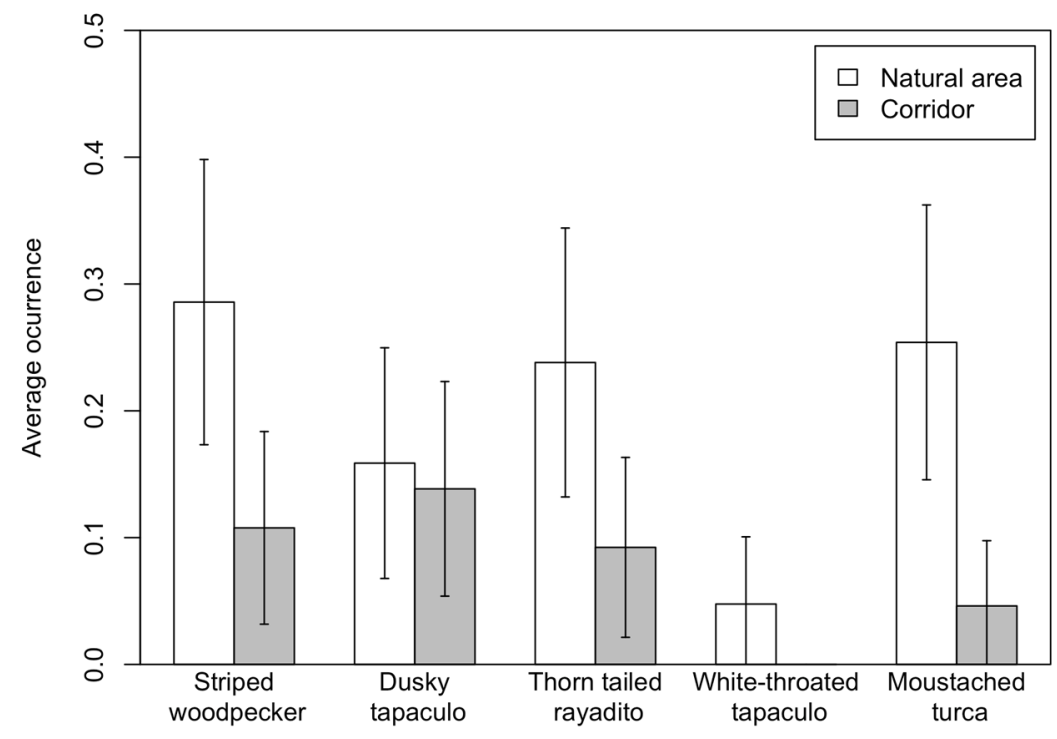

Figure 5. Average occurrence of indicator bird species in vegetation corridors within vineyards (C) and in adjacent natural areas (i.e., patches of natural vegetation near cultivated land).

\subsection{Effect of Corridor Attributes on Ecological Indicators}

For each ecological indicator (i.e., selected birds, geophytes, tree regeneration, and woody plant cover), different combinations of predictor variables were selected by the model selection routine out of the nine corridor attributes specified in the full model. Moreover, no unique predictor (see methods section for predictors) was shared by all the indicator species analyzed. For example, distance from the sampled sites in corridors to the nearest natural area was a significant predictor of the occurrence of the selected indicators, with a negative relationship with bird species and geophytes, but was only marginally significant correlation for woody plant cover (Figure 6, Supplementary Material Table S3). However, almost all of our selected indicators tended to decline with distance from the corridor to the neighboring natural area.

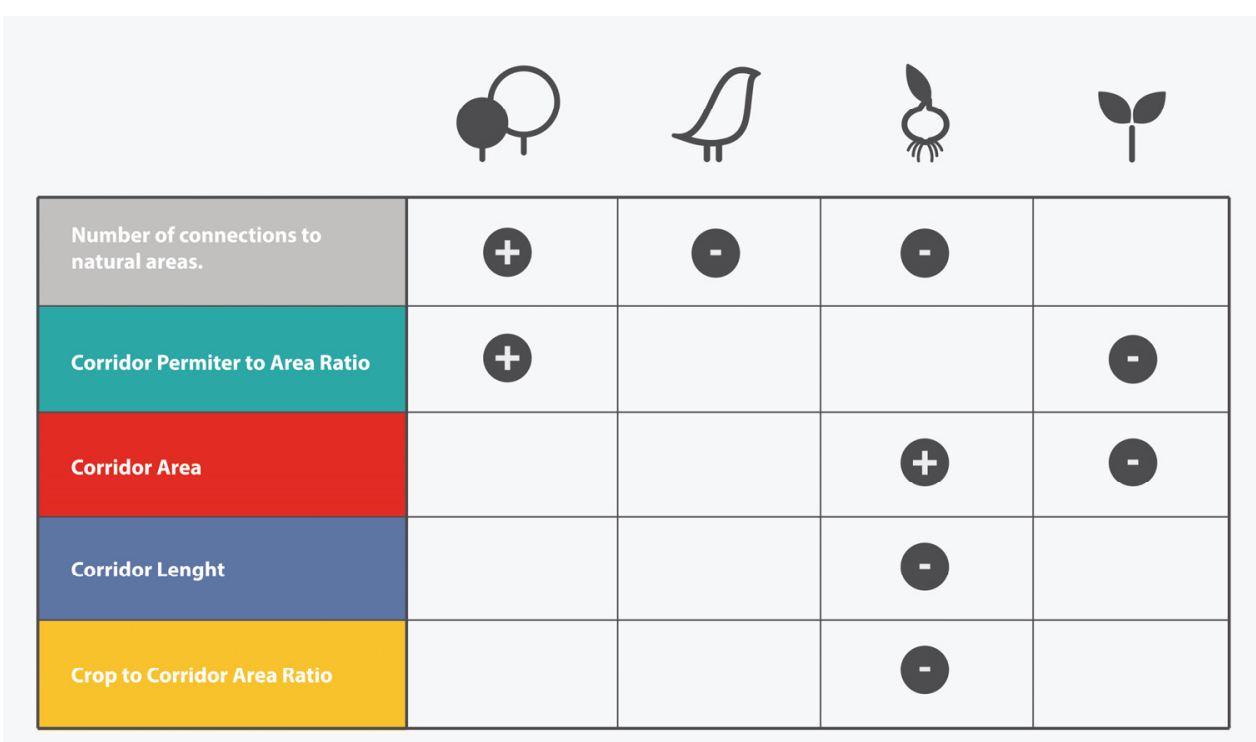

Figure 6. Relationship between ecological indicators and corridor traits. Colored circles indicate significant statistical relationships and (+) or (-) signs show positive or negative correlations. From left to right: "Tree regeneration", "Avian indicator species", "Geophytes", and "Woody plant coverage". 
Corridor area was positively correlated with the occurrence of geophytes but negatively related to tree regeneration (Supplementary Material Table S3). The perimeter-to-area ratio of corridors affected tree regeneration and showed a marginally significant relation with woody plant cover. Corridor length was a marginally significant predictor of tree regeneration but a significant predictor of the occurrence of geophytes (Supplementary Material Table S3). Finally, the high proportion of cultivated-area to corridor-area explained the lower occurrence of geophytes (Figure 6, Supplementary Material Table S3).

\section{Discussion}

Currently, a major challenge for conservation on rural lands is to move towards more sustainable agriculture $[21,52]$. Therefore, we evaluated the performance of relevant landscape features, such as biological corridors, and transient ecological indicators of sustainability in vineyards of the Mediterranean-climate region of central Chile, within the Chilean winter rainfall biodiversity hotspot. Our analysis first showed that existing vegetation corridors, in vineyards of central Chile, were elongated remnants of natural vegetation remaining in adjacent areas where topography (e.g., steep slopes) limited the expansion of crops $[15,40]$. These native vegetation strips were not originally designed as "biological corridors" or for conservation purposes, nor intended to connect remnant natural areas; hence, they often ended in a cultivated site or close to a road nearby (e.g., see Figure 2). Corridors or vegetation strips in vineyards may be better described as prolongations of remnant patches, having an elongated shape advancing to the lowlands from surrounding hills, dominated by natural vegetation [53]. Therefore, in these corridor areas, we can track the loss and arrival of species and the transit of others.

Secondly, could these corridors function as habitats for different taxa, in terms of connectivity and facilitating movement in the rural landscape? According to studies that have addressed animal movements along biological corridors in prairies associated with forested areas, birds (such as rhinocryptids) in southern Chilean forests [54] and mammals in the California chaparral [29] make regular, non-territorial use (e.g., foraging and migration) of these habitats when they are at least $19.7 \mathrm{~m}$ wide. Consequently, some of the sampled corridors could potentially function for some bird and mammal species, to enhance their movements between the cultivated vineyards and surrounding natural areas. However, our results suggest that greater distance from the corridor to the natural remnant vegetation has negative consequences for the occurrence of the selected birds, geophytes, and woody plants. As hypothesized, based on island biogeography theory, we expected a decrease in the number of taxa away from the natural areas, inside the corridors. This is particularly relevant for Mediterranean climate areas, where natural regeneration is limited [55]. Restoring degraded vegetation, which is connected to natural remnant vegetation, will be more effective than establishing a new corridor beginning from a denuded area. Therefore, implementing restoration plans for these pre-existing vegetation strips would allow practitioners to improve functional corridors in the medium term, with less technical difficulty and economic cost.

Other corridor traits affect the selected indicators in different ways: woody plant cover and the number of tree seedlings are affected by the greater edge-to-interior ratio of corridors, probably because area is proportional to the perimeter of vegetation strips and, therefore, related to the edge effect, which increases adverse abiotic effects, facilitates plant invasions, and increases the pressure of exotic herbivores [56-58]. These factors can also explain why tree regeneration in corridors is negatively affected by area. Geophytes, instead, are favored by a greater area of the vegetation strip since many species occur naturally in canopy openings in forests and scrublands [59]; hence they tolerate some level of drought and sun exposure along corridor edges. For all these reasons, contrary to our hypothesis, wider corridors do not present a greater number of selected indicators.

The density of woody seedlings did not differ between corridors and remnant natural areas in the proximity of vineyards, indicating that seed dispersal (by wind or biotic vectors) still functions within corridors; corridors could operate as connectors for the plants in 
remnant forest areas. A possible explanation of why seed dispersal is not limited here is that many avian seed dispersers are habitat-generalist. Thus, these biotic dispersers are common in natural habitats but also in human-modified landscapes [60]. However, we were unable to find woody saplings in the corridors within vineyards. Seedling survival and establishment, under the current Mediterranean summer-dry conditions, seems to be extremely low, even in natural areas [55]; drought-related mortality, rather than restricted dispersal, may be a major cause of sapling rarity, as well as its low absence in corridors.

Finally, do vegetation strip corridors (prolongations of natural vegetation areas) within vineyards deliver benefits for biodiversity conservation? We found significant differences in the presence of biodiversity indicators, such as selected bird species, geophytes, and woody plant cover between natural remnants of sclerophyllous forest and corridors within vineyards. These differences suggest contrasting environmental conditions. In this context, it is important to note that although the vineyard's crop areas were originally considered in our study, these areas were not included in the analysis, due to the absence of quantitative data on the effect of the crop area on the selected ecological indicators. Despite these differences, existing vegetation strips in vineyards represent an important opportunity for biodiversity conservation and landscape connectivity, associated with the planned management and design of the vineyard landscape [25]. For example, in urban landscapes, smaller patches ( $<15 \mathrm{ha}$ ) contribute significantly to overall connectivity, which may have implications for future conservation efforts [33]. Vegetation strips create habitat heterogeneity in the agricultural landscape that could enhance the permeability to biodiversity of the entire productive matrix in wildlife-friendly farmland $[3,61]$, providing additional cultural nature's contributions to people [17-19]. These strips should be conserved and restored to significantly enhance and promote habitat quality and connectivity.

In light of our results, we propose the following recommendations to winegrowers and farmers who wish to receive the benefits of local biodiversity and related nature's contributions to people:

(1) Maintain and restore vegetation strip quality (habitat continuity and width) by reducing impact barriers, such as gaps without plant cover, and preventing corridors from ending in a cultivated area or road, thus avoiding ecological traps for wildlife [29].

(2) Move from a single farm scale towards a broader landscape scale for agricultural planning and decision making [62]. Connect different natural areas with management that goes beyond private property limits [10]. The pattern of alternating valleys and ridges trending east-west, connecting the Andes and Coastal ranges, that shape the landscapes in central Chile, favor the design and implementation of large-scale corridors. The frequency of creeks, irrigation canals, stream hedgerows, riparian buffers, along with the conservation of scattered remnant vegetation patches could be used favorably to provide connections among natural areas conserved in central Chile, at the scale of basins or valleys. These natural areas often occur within the land owned by wineries worldwide [18,19].

(3) Implement protections (herbivory exclusions and watering in extremely dry summers) for seedlings and saplings in vegetation corridors to maintain or enhance the contribution of propagule dispersal to the production of vegetation, which, in turn, facilitates the distribution of other organisms across productive areas, such as arthropod natural enemies [63].

(4) Use our selected ecological indicators to evaluate conservation and management impacts, considering that: (a) Birds, geophytes, and woody plant cover are, according to our results, acceptable indicators of corridor quality, compared to the surrounding natural, unmodified, ecosystems. This requires that productive and natural areas be considered integrated and connected components within management planning; and (b) On the other hand, geophyte and tree seedling occurrences (that were shown to be associated with most vegetation strip traits), could be considered good indicators of the ecological status of corridors, and they can be used to monitor the success of different models of corridor design. These ecological variables can be easily measured 
by farmers, thus avoiding specialized technical assistance, and can provide useful insights and guidance to land managers.

Using this approach, we could provide novel and natural solutions for the conservation of biodiversity in productive or even suburban and rural landscapes and for enhancing the positive interactions between productive systems and the surrounding natural vegetation patches, hence integrating natural areas with the productive landscape. This will ensure the conservation of key components of wildlife within cultivated land and ensure the delivery of biodiversity-dependent nature's contributions to people that may represent valuable inputs for crops [64,65].

Supplementary Materials: The following are available online at https://www.mdpi.com/article/ 10.3390/d13090447/s1, Figure S1: relation in log scale between corridor area $\left(\mathrm{m}^{2}\right)$ and perimeter (m). Table S1: description and characteristic of vegetation strips or corridor in the studied vineyards. Table S2: effects of corridor versus natural areas on ecological indicators. Model for birds and woody plant coverage are zero-inflated. Parameter estimates are incidence ratios or odds ratios, depending on the distributional assumption (Poisson and Binomal) and represent a difference between the corridor and natural area treatments. Table S3: parameter estimates for corridor attributes obtained after applying the model selection routine to each ecological indicator. Estimates are incidence ratios or odds ratios, depending on the distributional assumption of the model (Poisson and Binomal).

Author Contributions: Conceptualization, J.D.-F., N.P. and O.B.; funding acquisition, O.B.; methodology, J.D.-F., S.A., N.P. and J.L.C.-D.; data acquisition, J.D.-F., N.P., K.G., G.L.S., M.I.U. and C.B.; data analysis, S.A. and J.L.C.-D.; writing J.D.-F., S.A., C.G., M.R.-B., J.J.A. and J.L.C.-D.; review and editing, J.D.-F., S.A., M.R.-B., J.J.A. and J.L.C.-D. All authors have read and agreed to the published version of the manuscript.

Funding: This research was funded by ANID (Chile) PIA/AFB170008 to the Instituto de Ecología y Biodiversidad (IEB), ECOS180008 to JLC-D and MR-B, ANID/PIA/ACT192027 to JLC-D and SA, and ANID/REGIONAL/CERES/R19A1002 to JD-F. SA was funded by ANID/FONDECYT 1170995.

Data Availability Statement: Original data associated with this manuscript is available at the Figshare repository at https:/ / doi.org/10.6084/m9.figshare.15079302.

Acknowledgments: This is a contribution to the Wine, Climate Change and Biodiversity program. JLC-D is an associate researcher to the Instituto de Ecología y Biodiversidad (IEB-Chile). We acknowledge San Pedro de Tarapacá, Ventisquero, Cono Sur, Santa Carolina, Odfjell, Matetic, Veramonte, Santa Rita, Errázuriz, Caliterra, Apaltagua, Montes, Neyen, Concha y Toro, San Esteban, Viu Manent, Emiliana, Koyle, and Haras de Pirque vineyards.

Conflicts of Interest: The authors declare no conflict of interest.

\section{References}

1. Loos, J.; Abson, D.J.; Chappell, M.J.; Hanspach, J.; Mikulcak, F.; Tichit, M.; Fischer, J. Putting meaning back into “sustainable intensification". Front. Ecol. Environ. 2014, 12, 356-361. [CrossRef]

2. Geertsema, W.; Rossing, W.A.; Landis, D.A.; Bianchi, F.J.; Van Rijn, P.C.; Schaminée, J.H.; Tscharntke, T.; Van Der Werf, W. Actionable knowledge for ecological intensification of agriculture. Front. Ecol. Environ. 2016, 14, 209-216. [CrossRef]

3. Grass, I.; Loos, J.; Baensch, S.; Batáry, P.; Librán-Embid, F.; Ficiciyan, A.; Klaus, F.; Riechers, M.; Rosa, J.; Tiede, J.; et al. Land-sharing/-sparing connectivity landscapes for ecosystem services and biodiversity conservation. People Nat. 2019, 1-11. [CrossRef]

4. Dainese, M.; Martin, E.A.; Aizen, M.A.; Albrecht, M.; Bartomeus, I.; Bommarco, R.; Carvalheiro, L.G.; Chaplin-Kramer, R.; Gagic, V.; Garibaldi, L.A.; et al. A global synthesis reveals biodiversity-mediated benefits for crop production. Sci. Adv. 2019, 5, 1-14. [CrossRef]

5. Chaplin-Kramer, R.; Sharp, R.P.; Mandle, L.; Sim, S.; Johnson, J.; Butnar, I.; Milà, I.; Canals, L.; Eichelberger, B.A.; Ramler, I.; et al. Spatial patterns of agricultural expansion determine impacts on biodiversity and carbon storage. Proc. Natl. Acad. Sci. USA 2015, 112, 7402-7407. [CrossRef]

6. Kehoe, L.; Romero-Muñoz, A.; Polaina, E.; Estes, L.; Kreft, H.; Kuemmerle, T. Biodiversity at risk under future cropland expansion and intensification. Nat. Ecol. Evol. 2017, 1, 1129-1135. [CrossRef]

7. IPBES. The Regional Assessment Report on Biodiversity and Ecosystem Services for the Americas; Secretariat of the Intergovernmental Science-Policy Platform on Biodiversity and Ecosystem Services: Bonn, Germany, 2018; p. 656. 
8. Myers, N.; Mittermeier Russell, A.; Mittermeier Cristina, G.; da Fonseca Gustavo, A.B.; Kent, J. Biodiversity hotspots for conservation priorities. Nature 2000, 403, 853-858. [CrossRef] [PubMed]

9. Armesto, J.J.; Manuschevich, D.; Mora, A.; Smith-Ramirez, C.; Rozzi, R.; Abarzúa, A.M.; Marquet, P.A. From the Holocene to the Anthropocene: A historical framework for land cover change in southwestern South America in the past 15,000 years. Land Use Policy 2010, 27, 148-160. [CrossRef]

10. Cox, R.L.; Underwood, E.C. The importance of conserving biodiversity outside of protected areas in mediterranean ecosystems. PLoS ONE 2011, 6, e0014508. [CrossRef]

11. Magrach, A.; Sanz, M.J. Environmental and social consequences of the increase in the demand for 'superfoods' world-wide. People Nat. 2020, 2, 267-278. [CrossRef]

12. Fisher, B.; Naidoo, R.; Ricketts, T. A Field Guide to Economics for Conservationists; Roberts and Company Publishers: Greenwood Village, CO, USA, 2015; 190p.

13. Castañeda, L.E.; Godoy, K.; Manzano, M.; Marquet, P.A.; Barbosa, O. Comparison of soil microbial communities inhabiting vineyards and native sclerophyllous forests in central Chile. Ecol. Evol. 2015, 5, 3857-3868. [CrossRef]

14. Simonetti, J.A.; Mella, J.E. Park size and the conservation of Chilean mammals. Rev. Chil. Hist. Nat. 1997, 70, 213-220.

15. Schulz, J.J.; Cayuela, L.; Echeverria, C.; Salas, J.; Rey Benayas, J.M. Monitoring land cover change of the dryland forest landscape of Central Chile (1975-2008). Appl. Geogr. 2010, 30, 436-447. [CrossRef]

16. Lovell, S.T.; Johnston, D.M. Creating multifunctional landscapes: How can the field of ecology inform the design of the landscape? Front. Ecol. Environ. 2009, 7, 212-220. [CrossRef]

17. Agnoletti, M.; Santoro, A. Cultural values and sustainable forest management: The case of Europe. J. For. Res. 2015, 20, 438-444. [CrossRef]

18. Santoro, A.; Venturi, M.; Agnoletti, M. Agricultural heritage systems and landscape perception among tourists. The case of Lamole, Chianti (Italy). Sustainability 2020, 12, 3509. [CrossRef]

19. Pulpón, Á.R.R.; Ruiz, M.D.C.C. Potential of vineyard landscapes for sustainable tourism. Geosciences 2019, 9, 472. [CrossRef]

20. Garibaldi, L.A.; Gemmill-Herren, B.; D’Annolfo, R.; Graeub, B.E.; Cunningham, S.A.; Breeze, T.D. Farming Approaches for Greater Biodiversity, Livelihoods, and Food Security. Trends Ecol. Evol. 2017, 32, 68-80. [CrossRef] [PubMed]

21. Pretty, J. Intensification for redesigned and sustainable agricultural systems. Science 2018, 362. [CrossRef]

22. Gerten, D.; Heck, V.; Jägermeyr, J.; Bodirsky, B.L.; Fetzer, I.; Jalava, M.; Kummu, M.; Lucht, W.; Rockström, J.; Schaphoff, S.; et al. Feeding ten billion people is possible within four terrestrial planetary boundaries. Nat. Sustain. 2020, 3, 200-208. [CrossRef]

23. Viers, J.H.; Williams, J.N.; Nicholas, K.A.; Barbosa, O.; Kotzé, I.; Spence, L.; Webb, L.B.; Merenlender, A.; Reynolds, M. Vinecology: Pairing wine with nature. Conserv. Lett. 2013, 6, 287-299. [CrossRef]

24. Garibaldi, L.A.; Carvalheiro, L.G.; Leonhardt, S.D.; Aizen, M.A.; Blaauw, B.R.; Isaacs, R.; Kuhlmann, M.; Kleijn, D.; Klein, A.M.; Kremen, C.; et al. From research to action: Enhancing crop yield through wild pollinators. Front. Ecol. Environ. 2014, 12, $439-447$. [CrossRef]

25. Márquez-García, M.; Jacobson, S.K.; Barbosa, O. Wine with a Bouquet of Biodiversity: Assessing Agricultural Adoption of Conservation Practices in Chile. Environ. Conserv. 2019, 46, 34-42. [CrossRef]

26. Caro, T. Conservation by Proxy: Indicator, Umbrella, Keystone, Flagship, and Other Surrogate Species; Island Press: Washington, DC, USA, 2010.

27. Bal, P.; Tulloch, A.I.T.; Addison, P.F.E.; McDonald-Madden, E.; Rhodes, J.R. Selecting indicator species for biodiversity management. Front. Ecol. Environ. 2018, 16, 589-598. [CrossRef]

28. Failing, L.; Gregory, R. Ten common mistakes in designing biodiversity indicators for forest policy. J. Environ. Manag. 2003, 68, 121-132. [CrossRef]

29. Hilty, J.A.; Merenlender, A.M. Use of Riparian Corridors and Vineyards by Mammalian Predators in Northern California. Conserv. Biol. 2004, 18, 126-135. [CrossRef]

30. Schulz, J.J.; Schröder, B. Identifying suitable multifunctional restoration areas for Forest Landscape Restoration in Central Chile. Ecosphere 2017, 8. [CrossRef]

31. Tewksbury, J.J.; Levey, D.J.; Haddad, N.M.; Sargent, S.; Orrock, J.L.; Weldon, A.; Danielson, B.J.; Brinkerhoff, J.; Damschen, E.I.; Townsend, P. Corridors affect plants, animals, and their interactions in fragmented landscapes. Proc. Natl. Acad. Sci. USA 2002, 99, 12923-12926. [CrossRef]

32. Haddad, N.M.; Bowne, D.R.; Cunningham, A.; Danielson, B.J.; Levey, D.J.; Sargent, S.; Spira, T. Corridor use by diverse taxa. Ecology 2003, 84, 609-615. [CrossRef]

33. Deslauriers, M.R.; Asgary, A.; Nazarnia, N.; Jaeger, J.A.G. Implementing the connectivity of natural areas in cities as an indicator in the City Biodiversity Index (CBI). Ecol. Indic. 2018, 94, 99-113. [CrossRef]

34. Butler, S.J.; Freckleton, R.P.; Renwick, A.R.; Norris, K. An objective, niche-based approach to indicator species selection. Methods Ecol. Evol. 2012, 3, 317-326. [CrossRef]

35. Morelli, F.; Pruscini, F.; Santolini, R.; Perna, P.; Benedetti, Y.; Sisti, D. Landscape heterogeneity metrics as indicators of bird diversity: Determining the optimal spatial scales in different landscapes. Ecol. Indic. 2013, 34, 372-379. [CrossRef]

36. Noss, R.F. Indicators for Monitoring Biodiversity: A Hierarchical Approach. Conserv. Biol. 1990, 4, 355-364. [CrossRef] 
37. Altamirano, T.A.; Ibarra, J.T.; Martin, K.; Bonacic, C. The conservation value of tree decay processes as a key driver structuring tree cavity nest webs in South American temperate rainforests. Biodivers. Conserv. 2017, 26, 2453-2472. [CrossRef]

38. Sieving, K.E.; Willson, M.F.; De Santo, T.L. Habitat Barriers to Movement of Understory Birds in Fragmented South-Temperate Rainforest. Auk 1996, 113, 944-949. [CrossRef]

39. Sekercioglu, Ç.H.; Ehrlich, P.R.; Daily, G.C.; Aygen, D.; Goehring, D.; Sandí, R.F. Disappearance of insectivorous birds from tropical forest fragments. Proc. Natl. Acad. Sci. USA 2002, 99, 263-267. [CrossRef] [PubMed]

40. Steel, Z.L.; Steel, A.E.; Williams, J.N.; Viers, J.H.; Marquet, P.A.; Barbosa, O. Patterns of bird diversity and habitat use in mixed vineyard-matorral landscapes of Central Chile. Ecol. Indic. 2017, 73, 345-357. [CrossRef]

41. Fuentes, E.R.; Otaiza, R.D.; Alliende, M.C.; Hoffmann, A.; Fuentes, E.R.; Otaiza, R.D.; Alliende, M.C.; Hoffmann, A.; Poiani, A. Shrub clumps of the Chilean matorral vegetation: Structure and possible maintenance mechanisms. Oecologia 1984, 62, 405-411. [CrossRef]

42. Arroyo, M.T.K.; Cavieres, L.; Marticorena, C.; Muñoz-Schick, M. Convergence in the Mediterranean Floras in Central Chile and California: Insights from Comparative Biogeography. In Ecology and Biogeography of Mediterranean Ecosystems in Chile, California, and Australia; Arroyo, M.T.K., Zedler, P.H., Fox, M.D., Eds.; Springer: New York, NY, USA, 1995; pp. 43-88. ISBN 978-1-4612-2490-7.

43. Root-Bernstein, M.; Bennett, M.; Armesto, J.J.; Ebensperger, L.A. Small mammals as indicators of cryptic plant species diversity in the central Chilean plant endemicity hotspot. Glob. Ecol. Conserv. 2014, 2, 277-288. [CrossRef]

44. Contreras, L.; Gutiérrez, J.R. Effects of the subterranean herbivorous rodent Spalacopus cyanus on herbaceous vegetation in arid coastal Chile. Oecologia 1991, 87, 106-109. [CrossRef]

45. Braun-Blanquet, J. Pflanzensoziologie. Grundzüge der Vegetationskunde, 3rd ed.; Springer: Berlin/Heidelberg, Germany, $1964 ;$ p. 865.

46. Zuur, A.F.; Saveliev, A.A.; Ieno, E.N. Zero-Inflated Models and Generalized Linear Mixed Models with R; Highland Statistics Ltd.: Newburgh, UK, 2012.

47. Burnham, K.P.; Anderson, D.R. Model Selection and Multimodel Inference: A Practical Information-Theoretic Approach; Springer: New York, NY, USA, 2002.

48. Jackman, S. Pscl: Classes and Methods for R Developed in the Political Science Computational Laboratory. United States Studies Centre, University of Sydney. Sydney, New South Wales, Australia. R Package Version 1.5.2. 2017. Available online: https:/ / github.com/atahk/pscl/ (accessed on 16 July 2021).

49. Hothorn, T.; Zeileis, A.; Farebrother, R.W.; Cummins, C.; Millo, G.; Mitchell, M. lmtest: Testing Linear Regression Models. 2018. Available online: https:/ / cran.r-project.org/web/packages/lmtest/index.html (accessed on 16 July 2021).

50. Calcagno, V.; Mazancourt, C. de glmulti: An R Package for Easy Automated Model Selection with (Generalized) Linear Models. J. Stat. Softw. 2015, 34, 1-29. [CrossRef]

51. Barton, K. MuMIn: Multi-Model Inference. R Package Version 1.43.6. 2019. Available online: https://cran.r-project.org/web/ packages/MuMIn/index.html (accessed on 16 July 2021).

52. Wanger, T.C.; DeClerck, F.; Garibaldi, L.A.; Ghazoul, J.; Kleijn, D.; Klein, A.M.; Kremen, C.; Mooney, H.; Perfecto, I.; Powell, L.L.; et al. Integrating agroecological production in a robust post-2020 Global Biodiversity Framework. Nat. Ecol. Evol. 2020, 4, 1150-1152. [CrossRef] [PubMed]

53. Beier, P. A rule of thumb for widths of conservation corridors. Conserv. Biol. 2019, 33, 976-978. [CrossRef]

54. Castellón, T.D.; Sieving, K.E. Landscape history, fragmentation, and patch occupancy: Models for a forest bird with limited dispersal. Ecol. Appl. 2006, 16, 2223-2234. [CrossRef]

55. Becerra, P.I.; González-Rodríguez, V.; Smith-Ramírez, C.; Armesto, J.J. Spatio-temporal variation in the effect of herbaceous layer on woody seedling survival in a Chilean mediterranean ecosystem. J. Veg. Sci. 2011, 22, 847-855. [CrossRef]

56. Holmgren, M.; Segura, A.M.; Fuentes, E.R. Limiting mechanisms in the regeneration of the Chilean matorral-Experiments on seedling establishment in burned and cleared mesic sites. Plant Ecol. 2000, 147, 49-57. [CrossRef]

57. Holmgren, M. Exotic herbivores as drivers of plant invasion and switch to ecosystem alternative states. Biol. Invasions 2002, 4, 25-33. [CrossRef]

58. Holmgren, M.; Celis-Diez, J.L.; Armesto, J.J. Box 5.10 Tree-seedling establishment in fragmented Mediterranean forests of central Chile. In Principles and Practice of Forest Landscape Restoration: Case studies from the drylands of Latin America, Newton, A.C., Tejedor, N., Eds.; IUCN: Gland, Switzerland, 2011; p. 153. ISBN 978-2-8317-1340-3.

59. Schiappacasse, F.; Peñailillo, P.; Yáñez, P.; Bridgen, M. Propagation studies on chilean geophytes. Acta Hortic. 2005, 673, 121-126. [CrossRef]

60. Vergara, P.M.; Armesto, J.J. Responses of Chilean forest birds to anthropogenic habitat fragmentation across spatial scales. Landsc. Ecol. 2009, 24, 25-38. [CrossRef]

61. Fischer, J.; Brosi, B.; Daily, G.C.; Ehrlich, P.R.; Goldman, R.; Goldstein, J.; Lindenmayer, D.B.; Manning, A.D.; Mooney, H.A.; Pejchar, L.; et al. Should agricultural policies encourage land sparing or wildlife-friendly farming? Front. Ecol. Environ. 2008, 6, 380-385. [CrossRef]

62. DeClerck, F.; Estrada-Carmona, N.; Garbach, K.; Martinez-Salinas, A. Biodiversity and Ecosystem Services of Agricultural Landscapes. In Agroecology for Food Security and Nutrition, Proceedings of the FAO International Symposium, Rome, Italy, 18-19 September 2014; FAO: Rome, Italy, 2014; pp. 140-157. 
63. Nicholls, C.I.; Altieri, M.A.; Parella, M. The effects of a vegetational corridor on the abundance and dispersal of insect biodiversity within a northern California organic vineyard. Landsc. Ecol. 2001, 16, 133-146. [CrossRef]

64. Garratt, M.P.D.; Senapathi, D.; Coston, D.J.; Mortimer, S.R.; Potts, S.G. The benefits of hedgerows for pollinators and natural enemies depends on hedge quality and landscape context. Agric. Ecosyst. Environ. 2017, 247, 363-370. [CrossRef]

65. Kremen, C.; Merenlender, A.M. Landscapes that work for biodiversity and people. Science 2018, 362. [CrossRef] [PubMed] 